\title{
Product Innovations and R\&D public funding: How to Handle Heteroscedasticity and Autocorrelation?
}

\author{
Martha Liliana Torres-Barreto
}

\begin{abstract}
This research was set out to analyze if the consequences of public funding for private $R \& D$ activities could be identified and measured through product innovations, and also, which issues should being bear in mind to build up a model that intends to explain such a relationship. As endogeneity was considered as a possibility between $R \& D$ public funding and product innovations reached by firms, we used an econometric procedure to test if it was present in the model, but we found no evidence of it. Instead we did found and correct serial autocorrelation and heteroscedasticity within our panel-data model, which consists of 3.500 Spanish firms during the years: 2000-2012. The panel belongs to ESEE (Spanish Annual Firms Strategy Survey). Preliminary findings may indicate that achieving product innovations in the past may influence the goal of obtaining new product innovations by the side of firms. In addition, we found a negative relationship between funding received and product innovations achieved. It may lead us to conclude that an increase on funding received is being used by firms to produce a different type of innovation, rather than the product innovation one. We now leave the floor open for further research that may include new variables in the model, as moderators of the relationship between R\&D public funding and product innovations achieved. Another important contribution to literature is based on the use of product innovations as a plausible measure of $R \& D$ results, when most of the literature is focused on patents and other bibliometric results.
\end{abstract}

Index Terms-Public funding, product innovation, heteroscedasticity, endogeneity, autocorrelation.

\section{INTRODUCTION}

Theoretical and empirical research efforts on studying the impact of public funding policies have been made during the last years [1]-[5], although, as stated by some authors, they are not enough considering the magnitude of resources that different governments spend on R\&D.

The importance of studying the impact of public R\&D funding relays not only on the amount of public money spent, but also on the impact it is supposed to produce within firms and in the society. This study is focused on firm's technological output, and in particular, on product innovations generated by $R \& D$ grant beneficiary firms. This kind of innovations are inherent to the organizations themselves, but also generate an impact on the technological ecosystem and consequently on society, since product

Manuscript received June 30, 2017; revised January 18, 2018. This work was partially supported by Universidad Industrial de Santander, Colombia and Universidad de las Islas Baleares, Spain.

M. Torres-Barreto is with Universidad Industrial de Santander, Colombia, belongs to the Research Group: Finance \& Management (e-mail: mitorres@uis.edu.co). innovations involve the creation of new or significantly improved ready-to-market products with new or improved technical characteristics or materials, or with improved functional characteristics, as well as products that encompass a simplified way of use [6].

The selection of product innovations as technological indicator of R\&D activity is also appropriate if the objective is to measure the effect of SMEs's R\&D effort. Many authors state that big firms tend to invest on process innovations since one of their strengths is cost reduction, while small and medium enterprises invest more on the searching of new products. Due to this heterogeneity in the innovative behavior of firms, big companies are still dominant on post-innovation markets, while smaller ones are likely to be pioneers on the new-product markets [7].

Another important aspect influencing the study of this technological effect is that product innovation could eventually stimulate additional investment from the side of the firm, which would contribute to minimize the market failure [8] by an spillover effect [9]. Results of the current research shed light on the effectiveness of R\&D public funding, and also pointed out the necessity of reinforcing certain capabilities or develop some resources within firms in order to potentiate the effect of $R \& D$ grants on the number of product innovations obtained, information that could be useful for policy makers as well as for CEOs.

\section{PREvious WORK IN THE FIELD AND EXTANT GAPS}

Technological impact of public R\&D investment could be measured as a function of a new or improved technological skill or by a technological gap closed, or by means of a new technology developed and the subsequent technological progress achieved [10]. This improved technological skills will provide firms with the capability of generate new and significantly improved products that may help to reinforce competitive advantages of firms by means of differentiation [11]-[13]; allowing for an economic growth [14].

Authors studying the technological effect of R\&D funding have focused their work on: the originality of the innovations achived by recipient firms and its relationship with the profitability of those innovations [15]; the differences when considering diverse technological outcomes as patents, product or process innovation [16]; and the determinants of technological impact, as for example: cooperation among partners, level of novelty or type of industry [17].

Those previous studies share something in common: a positive relationship has been found between the reception of $\mathrm{R} \& \mathrm{D}$ funds and the technological effect experienced by firms [15]-[18]. There is also another common factor among 
previous studies: they mostly focus their attention on patents as an extended and consistent protection regime over countries, however, few authors use product innovations as a measure of $R \& D$ outcome. For this reason, and considering that product innovations are more frequent among SMEs that patents are, we call for a profound research regarding the use of product innovations as a measure of R\&D activity.

\section{RESEARCH DESIGN}

The importance of studying the impact of public R\&D funding relies not only on the amount of public money spent but also on the intended effects in both: firms and the society, as product innovation can enhance firms' competitive advantage; the offspring of products changes the technological ecosystem, and, new product introduction redefines patterns, habits and behaviors in society in general [19].

Moreover, product innovations as a technological indicator of $\mathrm{R} \& \mathrm{D}$ activity are also appropriate if the objective is to measure the effect of SMEs's R\&D effort. The process innovation behavior of big incumbent firms contrasts with small and medium enterprises who attempt to differentiate via new products. Due to this heterogeneity in the innovative activities of firms, big companies are still dominant on post-innovation markets, while smaller ones are likely to be pioneers on the new-product markets [7] Furthermore, product innovation can eventually stimulate private R\&D investment, which would contribute to minimize the market failure common in the appropriation of R\&D [9].

In the quest for measuring the technological impact of public R\&D investment, researchers can rely on outcomes as the function of new or improved skills, by a technological gap closed, by the use of a newly developed technology, or by the subsequent technological progress achieved [10]. Under these circumstances, firms developing new technological skills may harvest the returns in new processes or new products, which lead to a competitive advantage [11], [13].

Studies on the effect of R\&D funding analyze the originality and profitability of the resulting innovations [2] [17]; the differential effects when using diverse innovation outcomes [16]; and the mediating impact of industry and cooperation [17]. These previous studies have as common finding the positive relationship between the R\&D grants and the technological effect experienced by firms. Nonetheless, most of these studies focus their attention on the number of patents as an extended and consistent protection regime over countries, disregarding their potential shortcomings as R\&D output measure. Firstly, patents serve as protection mechanisms that prevent imitation from competitors. Notwithstanding, they have a preemptive scope by reinforcing the first mover advantage, although many of these patents may never become actual products. Secondly, usually complex products require more than one patent, which makes them overestimate the innovation performance of the firm. Thirdly, patents grant protection to inventions lying on a limited definition of innovation according to the Oslo Manual; which leaves products and technologies of lesser inventive activity unprotected. Finally, patenting decisions usually entail strategic decisions, thus, firms may opt out from patents and retain their technology as trade secrecy. On the contrary, product innovations are the most tangible expressions of the techniques and inventive capacity of the firm. They reveal whether the company knows or dominates the technology, so as they embody the firm's knowledge in actual outcomes. They represent the creation of new or significantly improved ready-to-market products, with new or improved technical characteristics or materials, or with improved functional characteristics, as well as products that encompass a simplified way of use [6]. At last, firms leery of revealing their knowledge through patents, are not that modest when disclosing their new products. For these reasons and the pervasiveness of product innovations in SMEs in opposition to patents we claim that:

Hypothesis: R\&D grants beneficiary firms obtain more product innovations than that not receiving grant support.

\section{METHODS EMPLOYED}

The study deals with a panel of 3.500 firms included in the Spanish Survey of Business Strategies (ESEE). The manufacturing companies were analized with more than ten employees through a pooled crossed section analysis including years 2000-2012. As a depent variable we used the number of product innovations (nip). The independet variable used was the amount of subsidies received by firms (ayudas), which was normalized using a log transformation. As control variable was chosen the normalized internal expenditure on R\&D (giid), the amount of hired personnel as a proxie of size of firms (paf), and a variable that indicates wether the firm perform R\&D or not (aid). Also were included dummies for years and sectors.

Since we wanted to test for endogeneity, we used a recognized procedure to verify and eventually correct this condition in our model. Endogeneity was perceived as a possible situation for the independent variable: product innovations reached by firm. In models with endogeneity, estimators are skewed and non consistent and might lead to erroneus conclusions. Nevertheless endogeneity could be treated and corrected when it is present in a model.

The procedure followed included a simutaneous equations model:

$$
\begin{aligned}
& Y=\beta_{0}+\beta_{1} H+\beta_{i} X_{i}+\mu \\
& H=\gamma_{0}+\gamma_{1} Z_{i}+\gamma_{j} Q_{j}+\vartheta
\end{aligned}
$$

where

$Y=$ Number of product innovations,

$H=$ Funding received for $\mathrm{R} \& \mathrm{D}$ activities

$X_{i}=$ Control variables ( $\mathrm{R} \& \mathrm{D}$ internal expenditure, firm size and an indicator of R\&D activity).

$Z_{i}=$ Insturmental variables

(variables that are related to the funding received but are not related to the product innovations achived by firms, in this case we used investment on machinery and investment on computers and hardware).

$Q_{j}=$ Control variables.

We test if $Z_{i}$ and $Q_{j}$ are independent of $Y$ by adding them to Equation (1) and evaluating the significance of their 
coefficients.

We regress Equation (2) and saved the estimated residuals. Those estimated residuals of Equation (2) were added to Equation (1) and we evaluated the significance of its regresion coeficient. If this is significant, then we can assure that the variable "Product Innovations" is endogenous.

We used xtreg command in STATA 12.0 which fits regression models to panel data. In particular we used the "re vce(robust)" option which requests the GLS randomeffects estimator and specifies the type of standard error reported, in this case errors that are robust to some kinds of misspecification.

\section{FINDINGS AND MAIN OUTCOMES OF RESEARCH}

\section{A. Correlations Analysis}

As it is seen in Table I, none of the correlations among variables is higher than 0,7 . The highest correlation is between the size of firms and its internal expenditure in R\&D activities $(0,68)$ which is still within plausible limits.

TABLE I: CORRELATIONS ANALYSIS OF VARIABLES INCLUDED IN THE MODEL

\begin{tabular}{llllll}
\hline \hline & ayudas_log & giid_log & paf_log & aid & invermaq \\
\hline ayudas_log & 1.00 & & & & \\
\hline giid_log & 0.53 & 1.00 & & & \\
\hline paf_log & 0.43 & 0.686 & 1.00 & & \\
\hline aid & 0.10 & 0.129 & 0.09 & 1.0 & 1.00 \\
\hline invermaq & -0.03 & -0.05 & -0.01 & -0.01 & \\
\hline \hline
\end{tabular}

Note: Every correlation is significant at a 5\% level. Source: The authors

TABLE II: RESULTS OF THE ENDOGENOUS TEST

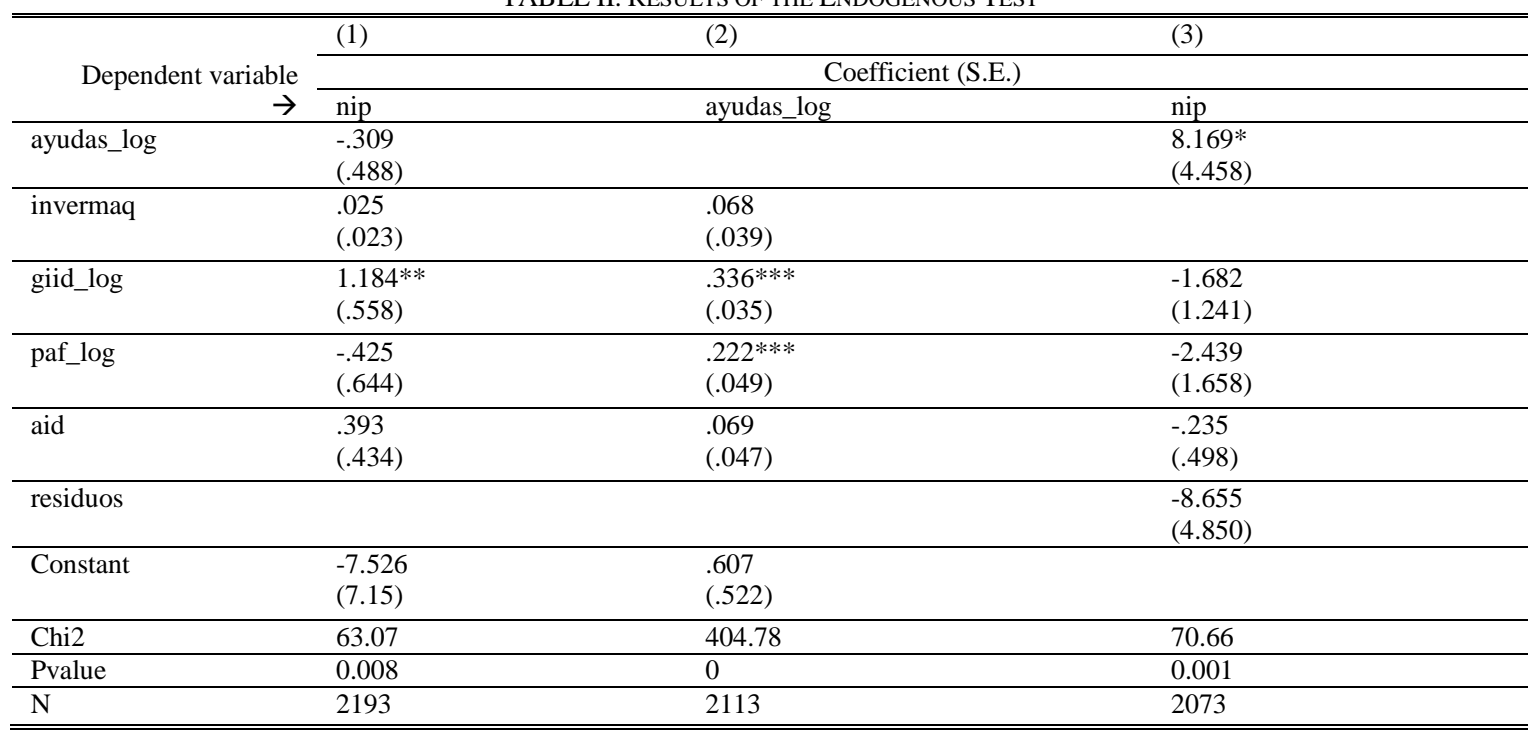

Notes: ${ }^{* * *}, * *$, show significance at the $1 \%$ and $5 \%$. Standard errors in parentheses. Controls by industrial sector and years. N: Number of observations. Source: The authors.

TABLE III: RESULTS FOR THE WOOLDRIDGE SERIAL AUTOCORRELATION TEST

\begin{tabular}{cll}
\hline Linear regression & Number of obs & $=1304$ \\
\hline$F(25,341)$ & $=$ &. \\
Prob $>F$ & $=$ &. \\
R-squared & $=0.0246$ \\
Root MSE & $=16.883$ \\
\hline
\end{tabular}

\begin{tabular}{lllll}
\hline \multicolumn{5}{c}{ (Std. err. adjusted for 342 clusters in ident) } \\
\hline D.nip & Coef & Std. Err. & $t$ & $P>t$ \\
\hline $\begin{array}{l}\text { ayudas_log } \\
\text { D1 }\end{array}$ & -.5146429 & .4996658 & -1.03 & 0.304 \\
\hline aid D1 & -1.502 .657 & 100.217 & -1.50 & 0.135 \\
\hline giid_log D1 & -.3039198 & .3646557 & -0.83 & 0.405 \\
\hline paf_log D1 & -573.565 & 3.820 .458 & -1.50 & 0.134 \\
\hline \hline
\end{tabular}

\section{B. Endogenous Test}

For the purpose of evaluating the relationship between funding received for R\&D activities and product innovations achieved by firms, the variable product innovations appear to be exogenous. This analysis can be found on Table II.

In the column 1 of the table you can see the results of Random-effects GLS regression where the instrumental variable: investment on machinery and computers was added to Equation 1. In The table presents the coefficient of the instrumental variable: "invermaq" is positive but no significant. It means that the variable accomplishes the first requisite, acting as an instrument.

Following this procedure we run Equation 2 and store its residuals. Results of the regression of Equation 2 are shown in column 2. As the coefficients of independent variables are significant, then, it makes them valid as identification variables.

In column 3 we added the residuals of previous regression 
to Equation 1 and run the model again. The coefficient of the residuals is not significant, consequently, the variable "product innovations" is considered to be exogenous [20].

\section{Autocorrelation Test}

Since serial correlation in linear panel-data models biases the standard errors and causes the results to be less efficient, we needed/was necessary to identify serial correlation in the idiosyncratic error term in our panel-data model. The Wooldridge test was used for this purpose. Table III reveals that the null hypothesis of serial correlation is strongly rejected, meaning our panel-data model has serial autocorrelation. Nevertheless it can be corrected with Ar1 or Ar2 depending on the model.

\section{Heteroscedasticity Test}

We run the xttest 3 function in Stata 12.0 with our panel data. Xttest3 calculates a modified Wald statistic for groupwise heteroscedasticity in the residuals of a fixed effect regression model. What we used for the regression specification was xtreg with a fixed effects model. As is shown in Table 4, our model confirms this condition, since the null hypothesis is strongly rejected. Bearing in mind this fact, and, contemplating that the existence of heteroscedasticity is a major concern in the application of regression analysis, as it can invalidate statistical tests of significance that assume that the modelling errors are uncorrelated and uniform, we plan to correct it in our model, along with the serial autocorrelation.

TABLE IV: RESULTS FOR THE HETEROSCEDASTICITY TEST

Modified Wald test for groupwise heteroscedasticity in fixed effect regression model

H0: sigma(i)^2 $=\operatorname{sigma}^{\wedge} 2$ for all $i$

$\operatorname{chi} 2(599)=1.0 \mathrm{e}+63$

Prob $>$ chi $2=0.0000$

\section{E. Fixed Effects controlling for Heteroscedasticity and} Autocorrelation

Dealing with the heteroscedasticity and autocorrelation, we used a method that handle these issues with robust standard errors. The Stata command -xtgee- estimates the parameters of a population-averaged longitudinal model and applied an autoregressive model, which specifies that the output variable is linearly-dependent of its own previous values and on a stochastic term.

This approach extends the generalized linear model (GLM) to longitudinal data. Results for the -xtgeeregression Ar2, are shown in Table $\mathrm{V}$ where you can see the independent variable -Ayudas- is highly significant in the model, meaning that a decrease of $1 \%$ on the grants received by firms may lead to an increase of 0.01358 , the number of product innovations achieved by firm.

Another interesting finding is a significant relationship between size of the firm and number of product innovations achieved. This is, when there is an increase of $1 \%$ on the personnel hired, there is also a decrease of 0.04019 on the product innovations achieved.

Finally, the constant term is positive and equal to 29.45 , which means that the best fit of the model do not start in zero, but it does in 29.45. It is also important to remind that estimations of this model are partial and coefficients are obtained when other data is not yet observed. Regression models allow us to imitate what scientists do in experimental labs: observing the behavior of certain variables "having everything else constant".

TABLE V: RESULTS FOR THE REGRESSION MODEL (SERIAL AUTOCORRELATION AND HETEROSKEDASTICITY CORRECTED). AR2

\begin{tabular}{lrl}
\hline \hline & $\begin{array}{r}\text { Coef. } \\
\text { (S.E.) }\end{array}$ \\
\hline ayudas_log & $-1,358$ & $* * *$ \\
\hline & $(-0,492)$ & -2 \\
\hline aid & $(-1,652)$ \\
\hline giid_log & 1,456 \\
\hline & $(-1,054)$ \\
\hline paf_log & $-4,019$ & $* *$ \\
\hline & $(-1,889)$ \\
\hline cons & 29.45 \\
\hline N & $(-1,919)$ \\
\hline Chi2 & 757 \\
\hline PValue & 65,73 \\
\hline \hline
\end{tabular}

Notes: $* * *, * *$, show significance at the $1 \%$ and $5 \%$. Standard errors in parentheses. Controls by industrial sector and year. N: Number of observations.

Source: The authors.

\section{DISCUSSION}

The purpose of this research was to study the influence of national funding on the product innovations obtained by Spanish firms, including certain control variables. In particular, we included size of the firm, internal expenditure on $R \& D$ and an indicator of R\&D activity by the side of the firms.

The main findings include:

- There is none endogeneity issue to be treated between the variables: product innovation and $R \& D$ funding received by the firms.

- There is a serial correlation in the model as well as an issue of heteroscedasticity that were treated and corrected.

- There is a negative and direct effect of $R \& D$ public funding on product innovations, as well as an isolated effect of size of the firm on product innovations.

- The corrected model implies that product innovations depend on their previous values, as for the scheme of an autoregressive model.

Previous findings may indicate, achieving product innovations in the past may influence the goal of obtaining new product innovations by the side of the firms. In addition, the negative relationship between funding received and product innovations achieved may lead to conclude that an increase on funding is being used by The Firms to produce a different type of innovation, rather than the product one.

Also further research may focus on testing dynamic models including lags on the independent variable to test if $\mathrm{R} \& \mathrm{D}$ funding received in previous periods may have a different effect on the product innovations achieved in the present.

As for the size of the firms (which also was found to have an inverse relationship with product innovations), we may 
conclude that small firms are focused on product innovations, while big companies are more prone to different types of intellectual property regimes.

The floor is now open to further research which might include new moderating variables in this basic model, considering that the endogeneity will not be an issue to be treated, and also that the observation of new variables should enhance the understanding of this phenomenon.

\section{REFERENCES}

[1] P. Hall and B. David, "Heart of darkness: Módeling public-private funding interactions inside the R\&D black box," Research Policy, pp 1165-1183, 2000.

[2] D. V. Pottelsberghe and B. Guellec, "The impact of public R\&D expenditure on business R\&D," Economics of Innovation and New Technologies, pp. 225-244, 2003.

[3] D. Hussinger and K. Czarnitski, "The link between R\&D subsidies, R\&D spending and technological performance," Issue Discussion paper $\mathrm{N}^{\circ}$ 04-56, ZEW Center for European Economic Research, 2004.

[4] E. Taymaz and E. Özçelik, "Does innovativeness matter for international competitiveness in developing countries? The case of Turkish manufacturing industries," Research Policy, pp. 409-425, 2004.

[5] M. Torres-Barreto, R. Mendez-Duron, and F. H. Perlines, "Technological impact of R\&D grants on utility models," R\&D Management, 2016.

[6] OCDE, Manual de Oslo, Guía para la recogida e interpretación de datos sobre innovación. Brussels: OCDE, 2005.

[7] X. Zuscovitch and E. Yin, "Is firm size conductive to R\&D choice? A strategic analysis of product and process innovations," Journal of Economic Behavior \& Organization, pp. 243-262, 1998.

[8] K. Arrow, "Economic wellfare and the allocation of resources for invention," NBER Chapters, pp. 609-626, 1962.

[9] M. García-Quevedo and J. Callejón, "Public subsidies to business R\&D: Do they stimulate private expenditures?" Environment and Planning C: Government and Policy, pp. 279-293, 2005.

[10] S., Joo, Y. Han, and H. Sohn, "Structural equation model for the evaluation of national funding on R\&D project of SMEs in consideration MBNQA criteria," Evaluation and Programing Planning, pp. 10-20, 2007.

[11] T., Cameron, H. Georgiou, and L Buisseret, "What difference does it make? Additionality in the public support of R\&D in large firms," Evaluation of Research and Innovation, pp. 587-600, 1995.

[12] S. Hewitt-Dundas and N. Roper, Measuring the Impact of Grant Support for Innovation: Panel Data Evidence for Irish Firms, Amsterdam: European Regional Science Association, 2005.

[13] A. Paton, D. Siegel, and D. Link, "An econometric analysis of trends in research joint venture activity," Managerial and Decision Economics, pp. 149-158, 2005.

[14] M. Porter, The Competitive Advantage of Nations, London: The Macmillan Press, 1990.

[15] P. Hanel, "Impact of government support programs on inovation, by Canadian manufacturing firms," presented at the International Conference: Evaluation Government Funded R\&D Activities, 2003.
[16] J. Mohnen and P. Mairesse, "The importance of R\&D for innovation and firm performance: A reassessment using French survey data," NBER working paper, vol. 10897, Cambridge, MA., 2004.

[17] B. Ebersberger, "The impact of public R\&D funding," Finland: Technical Research Centre of Finland, pp. 588-592, 2005.

[18] CDTI, Estudio Sobre el Impacto de la I+D+i en el Sector Productivo Español.: CDTI, 2009.

[19] J. Barney, "Firm Resources and sustained competitive advantageFirm Resources and sustained competitive advantage," Journal of Management, pp. 99-120, 1991.

[20] M. I. Gonzalez, "Como diagnosticar y corregir el problema de la endogeneidad," Poblaciòn y salud en Mesoamérica, 2006.

[21] A. R. Santos, A. Sales, P. Fernández, and A. M. Nichols, "Combining Challenge-Based Learning and Scrum Framework for Mobile Application Development," in Proc. the 2015 ACM Conference on Innovation and Technology in Computer Science Education, 2015, pp. 1989-194.

[22] Consejo Parlamento Europeo. European Paliament. [Online]. http://www.europarl.europa.eu/portal/es

[23] C. Martínez and M. Fernández. (2000) EDUTIC. [Online]. http://www.edutic.ua.es/wp-content/uploads/2012/06/La-practicaeducativa_291_300-CAP25.pdf

[24] M. Jou, C. Hung, and S. H. Lai, "Application of challenge based learning approaches in robotics education," International Journal of Technology and Engineering Education, vol. 7, no. 2, pp. 1-42, 2010.

[25] F. H. Perlines, "Las capacidades de las empresas y su orientación emprendedora," in Proc. ACEDE Anual Conferencia, Madrid, 2014, pp. 121-152.

[26] S. A. Chávez, "Behavioural additionality in the context of regional innovation policy in Spain," Management Policies and Practices, pp. 95-110, 2011

[27] M. Audrestch and D. Feldman, "Innovation in cities: Science-based diversity, specialization and localized competition," European Economic Review, pp. 409-429, 1999.

[28] M. Gonzalez, "Como diagnosticar y corregir el problema de la endogeneidad," Poblaciòn y salud en Mesoamérica, 2006.

[29] J. Hall, B. Griliches, and Z. Hausman, "Economic models for count data with an application to the patents-R\&D relationship," Econometrica, pp. 909-938, 1984.

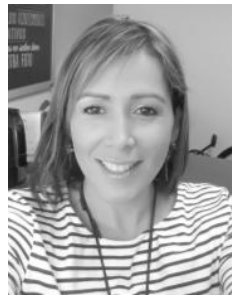

Martha L. Torres Barreto was born in Colombia, South America. She earns a PhD. on firm's strategy and marketing from Universidad de Castilla La Mancha, Spain. She also has a masters degree on industrial economics from Universidad Carlos III de Madrid, Spain and she has a specialist degree on IT economy from Universidad Carlos III de Madrid Spain.

She is actually an associate professor in Universidad Industrial de Santander, in Colombia and has published in international journals since 2010. Her previous experience as a practitioner at a technological center in Europe gives her a polyvalent approach which can be perceived in her manuscripts.

Her interest areas are: firm's strategy, resources and capabilities of firms and information and technology economical phenomenal analysis. 